\title{
Clinicopathological Correlates of Pancreatic Intraepithelial Neoplasia: A Comparative Analysis of 82 Cases With and 152 Cases Without Pancreatic Ductal Adenocarcinoma
}

\author{
Aleodor Andea, M.D., Fazlul Sarkar, Ph.D., Volkan N. Adsay, M.D. \\ Department of Pathology, Harper Hospital (AA, VNA), and The Karmanos Cancer Institute (FS), Wayne \\ State University School of Medicine, Detroit, Michigan
}

Pancreatic intraepithelial neoplasia is often associated with pancreatic ductal adenocarcinoma and is presumed to be its precursor. It has been difficult to determine the frequency of these lesions because until recently, there was no consensus regarding the terminology and criteria for their grading. Here we compare the frequency and clinical correlates of pancreatic intraepithelial neoplasia in pancreata involved by ductal adenocarcinoma and in benign ones, using the criteria put forward recently. We evaluated pancreatectomy specimens from 82 patients with ductal adenocarcinoma and 152 patients who underwent pancreatectomy for reasons other than primary malignancy (trauma, pancreatitis, and metastatic tumor to pancreas) for the presence, grade, and number of foci of pancreatic intraepithelial neoplasia. Cases were graded by the highest grade of pancreatic intraepithelial neoplasia focus identified. An average of 5.3 sections of pancreas was available for evaluation (range, 1-28 sections). Overall, the frequency of pancreatic intraepithelial neoplasia lesions in ductal adenocarcinoma patients, including Grade 1A (mucinous duct lesions), was $82 \%$, which was significantly higher than the one in benign pancreata $-54 \%, P<.001$. There was a progressive increase from normal pancreata to pancreatitis and to ductal adenocarcinoma in the frequency of overall pancreatic intraepithelial neoplasia lesions $(16 \%, 60 \%$, and $82 \%$, respectively) and Grade 3 pancreatic intraepithelial neoplasia $(0 \%$, $4 \%$, and $40 \%$, respectively). In most instances, in any given case of higher-grade pancreatic intraepithelial neoplasia lesion, there were also several foci

Copyright () 2003 by The United States and Canadian Academy of Pathology, Inc.

VOL. 16, NO. 10, P. 996, 2003 Printed in the U.S.A.

Date of acceptance: June 16, 2003.

Address reprint requests to: Volkan N. Adsay, M.D., Department of Pathology, Harper Hospital, 3990 John R, Detroit, MI 48201; fax: 313-9669348; e-mail: adsayv@med.wayne.edu.

DOI: 10.1097/01.MP.0000087422.24733.62 of lower grade lesions. The frequency of highergrade pancreatic intraepithelial neoplasia lesions ( 2 and 3) in pancreata resected for ductal adenocarcinoma was $59 \%$, significantly higher than in those without primary carcinoma $(17 \%)$. This progressive increase in frequency of pancreatic intraepithelial neoplasia from incidental pancreatectomies (presumed to have a nonpathologic pancreas) to pancreatitis (considered a risk factor for carcinoma) and to ductal adenocarcinoma constitutes an indirect support for the precancerous role attributed to pancreatic intraepithelial neoplasia lesions. The relatively high absolute occurrence of pancreatic intraepithelial neoplasia Grade 1A (mucinous duct lesions) in benign conditions (43\%) suggests that this group represents a combination of neoplastic and non-neoplastic lesions.

KEY WORDS: Carcinoma, Dysplasia, In situ, Intraepithelial, Neoplasia, Pancreas, Pancreatic.

Mod Pathol 2003;16(10):996-1006

Pancreatic ductal carcinoma is one of the most aggressive cancers, ranking fifth as the cause of cancer-related deaths in the United States. Annually, approximately 28,000 people are diagnosed with pancreatic cancer, and their 5-year survival rate does not exceed $4 \%$ (1). To improve the ominous course of this disease, one of the approaches would be to develop a reliable screening test that is capable of detecting precursor lesions (2). This type of approach has been successfully tried for colorectal neoplasia, for which screening for adenomas in high-risk groups now represents the standard of care. However, in pancreas, the study of early cancer is more challenging than in other organs because the pancreas inaccessibility precludes routine biopsy, and there remains also an incomplete understanding of its pathogenesis.

The first suggestion of precursor lesions for pancreatic carcinoma belonged to Sommers et al. (3), 
who noted an increase in pancreatic duct hyperplasia in patients with cancer compared with in those with benign pancreata. Subsequent studies confirmed these findings, pointing out that hyperplastic or dysplastic lesions of the pancreas are often found in association with adenocarcinoma (4-10). In a study of 227 cases of pancreatic carcinoma compared with 100 control autopsy cases without primary pancreatic cancer, Cubilla and Fitzgerald (4) noted that papillary hyperplastic lesions are more frequent in cancer cases than in nonneoplastic pancreata, and moreover, marked atypia and carcinoma in situ were noted exclusively associated with invasive carcinoma. Several studies have tried to evaluate the frequency of hyperplastic or dysplastic ductal lesions in normal pancreata from autopsy series $(4,11-16)$ or in cases with chronic pancreatitis (17-23). Nevertheless, until recently, it was difficult to determine the exact frequency of dysplasia because there was no consensus regarding the terminology and the criteria for their grading (2). More than 70 different terms belonging to several grading systems were used to describe focal proliferative and metaplastic lesions in the human exocrine pancreas (24). Even though investigators have suggested that some of these lesions may represent precursors of ductal carcinoma, the nomenclature included terms like metaplasia, hyperplasia, or hypertrophy that would imply a non-neoplastic lesion. Moreover, the confusing and redundant nomenclature did not permit direct comparison between different studies. Recently, a consensus has been reached that coined the term pancreatic intraepithelial neoplasia (PanIN) for these lesions (24), as originally proposed by Klimstra and Longnecker (25) and Brat et al. (26).
Our objective in the present study was to investigate the PanIN occurrence in a series of pancreata involved by primary ductal adenocarcinoma, compared with a series of pancreata resected for reasons other than primary pancreatic neoplasms, using the criteria put forth in this recent consensus study. Because several investigators established that chronic pancreatitis represents a risk factor for ductal adenocarcinoma $(18,19,27,28)$, we segregated the non-neoplastic pancreata group based on the presence or absence of chronic pancreatitis.

\section{MATERIALS AND METHODS}

\section{Selection of Cases}

From the files of Detroit Medical Center and Karmanos Center Institute, we selected 234 patients with primary pancreatic ductal adenocarcinoma and non-neoplastic pancreatic pathology. The cases selected fell into 2 diagnostic categories: 82 consecutive cases of pancreatic ductal adenocarcinoma (35\%) covering the period 1983-2000 and 152 consecutive cases of non-neoplastic pancreata (65\%) spanning the period 1977-2000 (Table 1). The non-neoplastic group was heterogeneous and included 86 cases of chronic pancreatitis (37\%), 36 cases (15\%) in which the resected pancreatic tissue did not reveal any pathology (including 19 cases with incidental pancreatectomies caused by traumatic events i.e., fire arm lesions), and 30 cases with secondary tumors involving the pancreas or peripancreatic tissue (13\%). In 212 cases $(91 \%)$, the patients underwent a pancreatectomy procedure, and in 22 cases $(9 \%)$, a pancreatic biopsy was performed. We assessed each case from the non-

Table 1. Distribution of Cases, Average Number of Pancreatic Slides Examined Per Case and Surgical Procedure in Various Diagnostic Categories

\begin{tabular}{|c|c|c|c|c|}
\hline \multirow{2}{*}{ Diagnostic Group } & \multirow{2}{*}{ Number of Cases (\%) } & \multirow{2}{*}{$\begin{array}{c}\text { Number of } \\
\text { Slides } \\
\text { Examined/Case } \\
\text { [Mean (range)] }\end{array}$} & \multicolumn{2}{|c|}{ Procedure } \\
\hline & & & Resection Number (\%) & Biopsy Number (\%) \\
\hline Non-neoplastic pancreas & $152(65 \%)$ & $4.57(1-38)$ & $130(86 \%)$ & $22(14 \%)$ \\
\hline "Normal" Pancreas & $36(15 \%)$ & $3.36(1-30)$ & $33(92 \%)$ & $3(8 \%)$ \\
\hline Trauma (GSW) & $19(8 \%)$ & $1.57(1-3)$ & $19(100 \%)$ & $0(0 \%)$ \\
\hline Other & $17(7 \%)$ & $5.35(1-30)$ & $14(82 \%)$ & $3(18 \%)$ \\
\hline Pancreatitis & $86(37 \%)$ & $5.69(1-38)$ & $69(80 \%)$ & $17(20 \%)$ \\
\hline Secondary tumors & $30(13 \%)$ & $2.8(1-9)$ & $28(93 \%)$ & $2(7 \%)$ \\
\hline $\begin{array}{l}\text { Gastric } \\
\text { adenocarcinomas }\end{array}$ & $12(5 \%)$ & $2.31(1-5)$ & $12(100 \%)$ & $0(0 \%)$ \\
\hline RCC & $5(2 \%)$ & $5.2(2-9)$ & $5(100 \%)$ & $0(0 \%)$ \\
\hline $\begin{array}{l}\text { Colon } \\
\text { adenocarcinomas }\end{array}$ & $4(2 \%)$ & $1.75(1-3)$ & $3(75 \%)$ & $1(25 \%)$ \\
\hline GIST & $2(1 \%)$ & $3.5(3-4)$ & $2(100 \%)$ & $0(0 \%)$ \\
\hline Unknown primary & $3(1 \%)$ & $2.33(1-4)$ & $3(100 \%)$ & $0(0 \%)$ \\
\hline Other $^{1}$ & $4(2 \%)$ & $3(1-5)$ & $3(75 \%)$ & $1(25 \%)$ \\
\hline Pancreatic DA & $82(35 \%)$ & $6.71(1-28)$ & $82(100 \%)$ & $0(0 \%)$ \\
\hline Total & 234 & $5.32(1-38)$ & $212(91 \%)$ & $22(9 \%)$ \\
\hline
\end{tabular}

GSW, gunshot wound; RCC, renal cell carcinoma; GIST, gastrointestinal stromal tumor; DA, ductal adenocarcinoma.

All percentages are rounded to the nearest integer.

${ }^{1}$ Lymphoma (1), Merkel cell carcinoma (1), granular cell tumor of common bile duct (1), retroperitoneal leiomyosarcoma (1). 
neoplastic category for the presence of pancreatic fibrosis and atrophy to establish what percentage from the secondary tumor group had associated chronic pancreatitis changes and also to ascertain that the "normal" pancreata group actually lacked chronic pancreatitis.

In the neoplastic group we selected only cases of ductal adenocarcinoma; other primary pancreatic tumors were excluded. We also eliminated from the secondary tumor group cases with ampullary or duodenal carcinoma invading into the pancreas. Overall, an average number of 5.32 (range, 1-38) sections of pancreas per case were available for evaluation, and this figure varied widely across different diagnostic groups: 3.36 slides/case in "normal" pancreata, 5.69 slides/case in chronic pancreatitis, 2.8 slides/case in secondary tumors, and 6.71 slides/case in pancreatic ductal adenocarcinoma (Table 1).

\section{Data Collection}

For all selected cases, we reviewed the pathology reports and recorded the demographic parameters (age, gender, race) and also the location of the resected pancreatic tissue (head, body, or tail). When clinical data were available, history of diabetes, smoking, or alcohol abuse were also recorded. In each of the selected cases, all available slides were evaluated by two of the authors (AA and VA) for the presence, grade, and number of foci of $\mathrm{Pa}-$ nIN lesions using the four-tier classification put forth recently (24). Borderline lesions that were difficult to classify were graded by consensus. We assigned to each case the highest grade of PanIN lesion that was identified, regardless of whether lower grade lesions were present. In other words, a case of a given PanIN grade could also contain areas with lesions of lower grade. For example, a case classified as Grade 2 might also contain PanIN 1A or 1B lesions but no PanIN 3 (Table 2). However, in documenting the "absolute" frequencies of each PanIN grade, any PanIN lesion present in these cases was included in the calculation (irrespective of whether they had additional lesions of higher grade). In evaluating the number of foci of PanIN, any involved duct that was not clearly connected to another was counted as a separate focus. Because in cases with ductal adenocarcinoma it is often difficult to distinguish between PanIN 3 foci and cancerization of ducts or even infiltrative large-duct units, we identified as high-grade PanIN lesions only those located distantly from the infiltrative tumor, surrounded by pancreatic parenchyma. A particular challenge was posed by the discrimination between foci of high-grade PanIN (2 or 3) and reactive inflammatory changes in the cases with atrophic pancreatitis. Although this differentiation is at times very difficult, we found a couple of criteria to be helpful. Inflammatory reaction induces changes mainly in cytology but not as many changes in architecture. As a consequence, reactive ducts may have significant cytological atypia mimicking that seen in PanINs 2 and 3 lesions but lack the distinctive micropapillary architecture, loss of polarity, tufting, and stratification characteristic of PanIN lesions. In reactive cytological atypia, despite the presence of nuclear enlargement and nucleolar prominence, the nuclei are often round with smooth contours and finely dispersed chromatin, and the cytoplasm is eosinophilic. Finally, in the presence of a significant inflammatory infiltrate, especially composed of PMNs, the diagnosis of reactive change was favored over dysplasia.

\section{Data Analysis and Statistical Methods}

Individual $t$ statistics and $P$ values were obtained to assess the differences in the mean values of the continuous variables (age and number of slides examined per case) between various diagnostic groups and also between cases with PanIN and without PanIN lesions. To determine statistical significance, we used a conservative Bonferroni correction or Tamhane's T2 method when equal variance was not assumed, to ensure that the combined Type I error probability when performing multiple tests was 0.05 .

The association between the diagnostic categories ranked normal, pancreatitis, secondary tumors, and pancreatic ductal adenocarcinoma and frequency of PanIN-positive cases was assessed by Kendall's tau coefficient. Separate $\chi^{2}$ tests were performed to correlate PanIN frequency with gender, race, and history of smoking, alcohol abuse, and

Table 2. Methodology Used for Grading the Cases

\begin{tabular}{|c|c|c|c|c|c|}
\hline & & \multicolumn{4}{|c|}{ PanIN Lesion(s) Identified in a Given Case } \\
\hline & & $1 \mathrm{~A}$ & $1 \mathrm{~B}$ & 2 & 3 \\
\hline \multirow{4}{*}{$\begin{array}{l}\text { PanIN grade assigned } \\
\text { to the case }\end{array}$} & $1 \mathrm{~A}$ & Present & Absent & Absent & Absent \\
\hline & $1 \mathrm{~B}$ & May be present & Present & Absent & Absent \\
\hline & 2 & May be present & May be present & Present & Absent \\
\hline & 3 & May be present & May be present & May be present & Present \\
\hline
\end{tabular}

PanIN grade assigned to a given case represented the grade of the highest PanIN lesion identified in that case. 
diabetes. When the expected frequency was $<5$, Fisher's exact test was used.

To assess the independent influence of pancreatic diagnostic categories and various demographic variables (age, gender, race, and history of smoking, alcohol abuse, and diabetes) on the proportion of PanIN-positive cases, we used a multivariate logistic regression model (29) with the diagnostic categories and demographic variables as the independent variables and the logit of PanIN probability as the dependent variable. The number of pancreatic slides examined in each case was variable across different diagnostic categories. Therefore, to control for differences in frequency of occurrence of PanIN that are produced by variations in sampling of the organ, we included the number of slides examined as an independent variable in our multivariate model.

\section{RESULTS}

A total of 908 foci of PanIN were identified in 149 of 234 cases $(64 \%)$ and were graded according to published criteria (24). Representative examples of the four PanIN grades identified in our series are displayed in Figure 1. In 53\% of the cases, the pancreatic tissue examined originated from the head of the pancreas (the patient underwent a pancreatoduodenectomy procedure or the biopsy was directed toward the head of the pancreas), whereas in $29 \%$ of the cases, it was obtained from the tail of the organ (from distal pancreatectomies procedures). The precise location was unknown in $18 \%$ of the cases because either a total pancreatectomy was performed ( $5 \%$ of cases) or the type of surgery was not available ( $12 \%$ of cases). If we consider only the PanIN-positive cases, the average number of PanIN foci detected in each case (PanIN density), expressed as number of PanIN lesions per slide of pancreatic tissue examined, was 1.23 foci/slide. This number was lower within the "normal" pancreata group ( 0.48 foci/slide) and higher in chronic pancreatitis, secondary tumors and pancreatic carcinoma groups $(1.45,1.56$, and 1.1 foci/slide, respectively). An ANOVA test with posthoc Tamhane's T2 correction revealed significant statistical differences in PanIN lesion density between socalled normal pancreata on one side and secondary tumors $(P<.0001)$, chronic pancreatitis $(P=.03)$, and pancreatic carcinoma $(P=.002)$ on the other side.

Table 3 displays the proportion of PanIN-positive cases, including detailed PanIN grades in different diagnostic categories. The ductal adenocarcinoma group had a significantly higher frequency of cases with PanIN than the group with no primary malignancy ( $82 \%$ versus $54 \%, P<.0001$ ). There was a progressive increase in the frequency of cases with PanIN from so-called normal pancreata $(28 \%)$ to secondary tumors and chronic pancreatitis $(60 \%$ and $63 \%$, respectively) and to ductal adenocarcinoma (82\%). Kendall's tau coefficient of correlation between the frequency of PanIN-positive cases and diagnostic category was $0.363, P<.0001$. Interestingly, there was no significant difference in the frequency of occurrence of PanIN between cases with chronic pancreatitis (63\%) and the secondary tumors group (60\%), $P=.78$. From a total of 30 cases of secondary tumors, 18 cases $(60 \%)$ were associated with atrophy and fibrosis of the pancreas, whereas 12 cases $(40 \%)$ had an unremarkable pancreas. In this group, the cases of secondary tumors associated with chronic pancreatitis had a higher frequency of PanIN than did cases with an unremarkable pancreas ( $72 \%$ versus $42 \%$ ); however, this difference was not statistically significant $(P=$ .09), probably related to the low number of observations. This result suggests that the increased frequency of PanIN-positive cases in the secondarytumors diagnostic category, compared with in the so-called normal category, may be partially related to the presence of chronic pancreatitis in $60 \%$ of these cases.

The distribution of PanIN grades across pancreatic diagnostic categories showed significant differences. The cases with so-called normal pancreata displayed only PanIN 1 as the highest grade $(28 \%$; $1 \mathrm{~A}=13 \%, 1 \mathrm{~B}=15 \%$ ) and no PanIN 2 or 3 lesions. The cases with pancreatitis exhibited predominantly PanIN 1 lesions (38\%; $1 \mathrm{~A}=26 \%, 1 \mathrm{~B}=13 \%$ ), but a significant proportion also displayed PanIN 2 (20\%), and only a few exhibited PanIN 3 lesions (5\%). The ductal adenocarcinoma group had a frequency of PanIN 1 and PanIN 2 (24\% and 18\%, respectively) that was similar to that of pancreatitis cases; however, $40 \%$ of cases displayed PanIN 3 lesions. A representative example of PanIN 3 from a case of chronic pancreatitis is illustrated in Figure 1D. The distribution of grades in secondary tumors group resembled the one in chronic pancreatitis; the prevalence of PanIN 1, 2, and 3 lesions was 43\%, $13 \%$, and $3 \%$, respectively. The low incidence of PanIN 1A lesions in some of the categories is the result of our convention in assigning to each case the highest grade of PanIN found and does not imply that these lesions were rare. Actually, in most instances, cases with high-grade PanIN exhibited also foci of $1 \mathrm{~A}$ and $1 \mathrm{~B}$ grade lesions. The absolute frequency of PanIN 1A lesions (that is, the proportion of cases exhibiting PanIN 1A lesions, irrespective of the presence of higher grade PanIN) was $43 \%$ in both pancreata without and with ductal adenocarcinoma.

Figure 2 displays the correlation between age and proportion of cases involved by PanIN. Overall, 


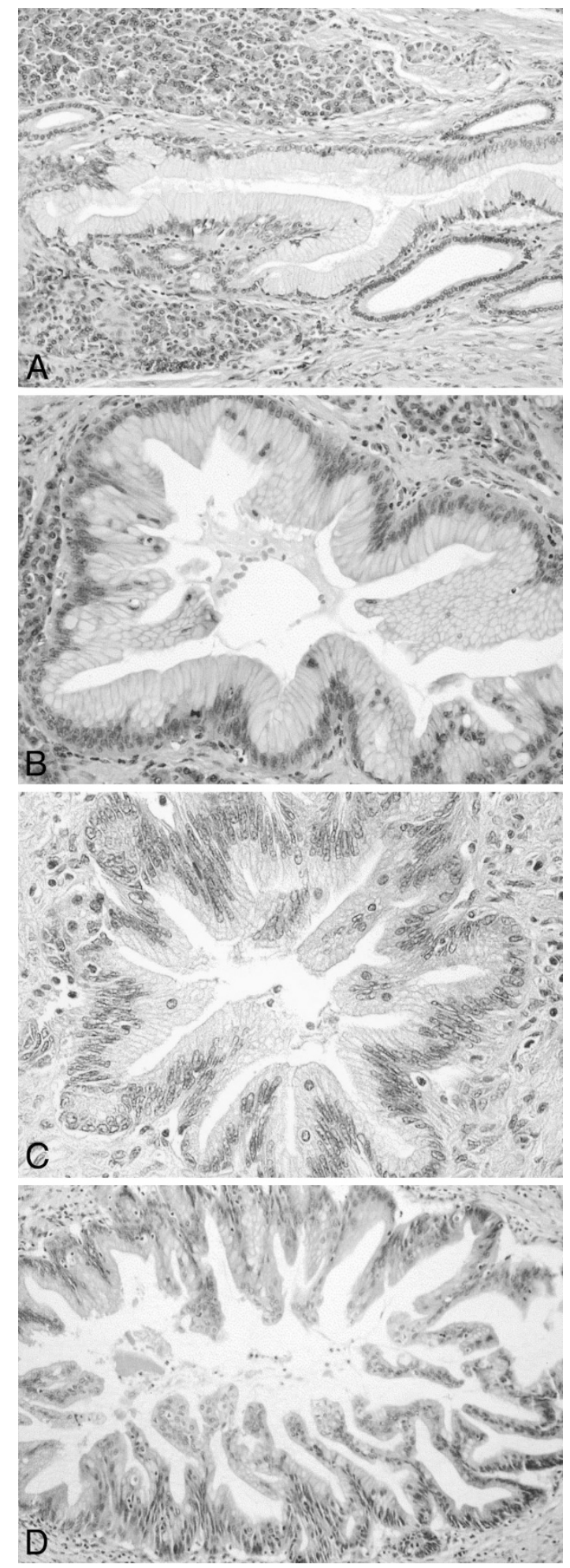

FIGURE 1. Representative examples of the four PanIN grades. A, PanIN 1A. Flat epithelial lesions with tall columnar cells and abundant supranuclear mucin. The nuclei are basally located and bland. B, PanIN 1B. Same cytology as PanIN 1A, but with papillary, micropapillary, or basally pseudostratified architecture. C, PanIN 2. Often papillary, rarely, can be flat. Show loss of cellular polarity nuclear stratification, crowding, enlarged nuclei and hyperchromatism. When present, mitoses are normal. D, PanIN 3. Equivalent to CIS, papillary, micropapillary, or cribriform architecture. Shows budding off of small clusters of cells into the lumen, luminal necrosis. Significant degree of atypia is present with apical and abnormal mitoses. This lesion is from a 43-year-old male with chronic pancreatitis and no evidence of invasive cancer on the distal pancreatectomy resection specimen. there was a significant direct correlation between age groups and PanIN frequency (Kendall's tau correlation coefficient $=0.3, P<.0001$ ). The average age of patients with and without PanIN lesions was 60.4 and 49.3 years, respectively, $P<.0001$. The mean age in ductal adenocarcinoma cases in our series was 66.7 years, significantly higher than the mean ages in the so-called normal and chronic pancreatitis categories (40.4 years, $P<.0001$; and 51.5 years, $P<.0001$, respectively; Table 4 ). As a result, the observed progressive increase in PanIN frequency that was noted from "normal" pancreata to pancreatitis and to ductal adenocarcinoma may be related partially to the increase in mean age. Therefore, to investigate the independent correlation between pancreatic pathology and frequency of PanIN-positive cases, we attempted to correct for differences in age distribution between diagnostic categories by including the age in a multivariate model.

The correlation between the number of slides examined in each case and PanIN frequency is illustrated in Figure 3. There is a progressive increase in the proportion of PanIN-positive cases with increase in the number of slides examined, suggesting a sampling phenomenon. Because there were differences in the average number of slides examined in various diagnostic categories, from 3.36 slides/case in so-called normal pancreata to 6.7 slides/case in ductal adenocarcinoma (Table 1), similar to the case with age, to investigate the independent correlation between pancreatic pathology and PanIN frequency, we attempted to correct for nonuniform sampling by including the number of slides examined as an independent variable in our model.

We did not find any statistically significant correlations between PanIN frequency and gender, race, history of diabetes, smoking, and alcohol abuse (Table 5). There was a trend for a higher proportion of PanIN-positive cases in females versus males ( $70 \%$ versus $59 \%$, respectively, $P=.1)$. For the history of diabetes, smoking, and alcohol abuse, the lack of statistical significance may be the result of the low number of cases in which these data were available (diabetes, smoking, and alcohol consumption histories were recorded in 57, 70, and 65 cases respectively). In the cases in which the location of PanIN foci was known, there was a trend for PanIN to occur more often in the head than in the tail of the pancreas ( $72 \%$ versus $60 \%$, respectively, $P$ $=.1$; Table 6 ). When only cases with ductal adenocarcinoma were considered, PanIN lesions were more frequently associated with carcinoma of the pancreatic head $(53 / 63 ; 84 \%)$ than of the tail $(9 / 13$; $69 \%), P=.2$.

A multivariate logistic regression model correlating the frequency of PanIN-positive cases with di- 
Table 3. Frequency of PanIN-Positive Cases (highest grade PanIN lesion used for assigning grade) and Average Number of PanIN Foci Per Case in Different Diagnostic Groups

\begin{tabular}{|c|c|c|c|c|c|c|c|}
\hline Diagnostic Group & $\begin{array}{l}\text { Number } \\
\text { of Cases }\end{array}$ & $\begin{array}{l}\text { Mean Number of } \\
\text { Foci/Case (range) }\end{array}$ & PanIN (\%) & PanIN 1A (\%) & PanIN 1B (\%) & PanIN 2 (\%) & PanIN 3 (\%) \\
\hline Non-neoplastic & 152 & $4.9(1-35)$ & $82(54 \%)$ & $28(18 \%)$ & $28(18 \%)$ & $21(14 \%)$ & $5(3 \%)$ \\
\hline Normal & 36 & $2.2(1-6)$ & $10(28 \%)$ & $4(13 \%)$ & $6(15 \%)$ & 0 & 0 \\
\hline Pancreatitis & 86 & $5.96(1-35)$ & $54(63 \%)$ & $22(26 \%)$ & $11(13 \%)$ & $17(20 \%)$ & $4(5 \%)$ \\
\hline Sec Tumors & 30 & $3.5(1-10)$ & $18(60 \%)$ & $2(7 \%)$ & $11(37 \%)$ & $4(13 \%)$ & $1(3 \%)$ \\
\hline With CP & 18 & $4.38(1-10)$ & $13(72 \%)$ & 0 & $10(56 \%)$ & $2(11 \%)$ & $1(6 \%)$ \\
\hline No CP & 12 & $1.4(1-2)$ & $5(42 \%)$ & $2(17 \%)$ & $1(8 \%)$ & $2(17 \%)$ & 0 \\
\hline DA & 82 & $7.55(1-35)$ & $67(82 \%)$ & 3 (4\%) & $17(21 \%)$ & $15(18 \%)$ & $33(40 \%)$ \\
\hline Total & 234 & $6.1(1-35)$ & $149(64 \%)$ & $31(13 \%)$ & 45 (19\%) & $36(15 \%)$ & $38(16 \%)$ \\
\hline
\end{tabular}

$\mathrm{CP}$, chronic pancreatitis; DA, pancreatic ductal adenocarcinoma.

All percentages are rounded to the nearest integer.

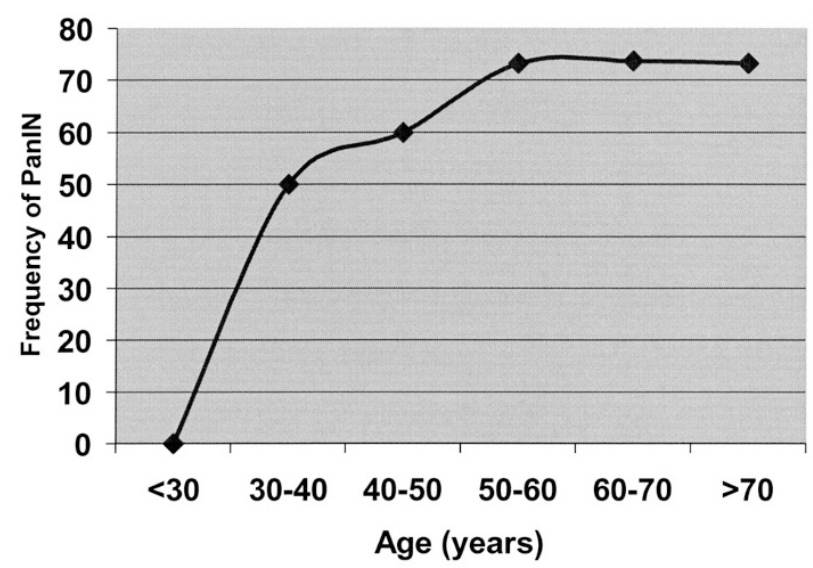

FIGURE 2. Correlation of age with PanIN frequency. Kendall's tau correlation coefficient $=0.3, P<.0001$.

agnosis, number of examined slides, and age is presented in Table 7 . The model shows that controlling for sampling variable (i.e., the number of slides examined in each case) and age, there is a significant independent correlation between the diagnostic category and PanIN frequency. The adjusted odds ratios for having PanIN lesions in pancreatitis and secondary-tumor groups versus normal were 3.3 and 3.05 respectively, and in the primary ductal adenocarcinoma versus "normal" were 4.7. Secondary tumors and chronic pancreatitis had a similar probability of PanIN occurrence, probably caused in part by the associated pancreatic fibrosis and atrophy that were present in $60 \%$ of metastatic tumors. The number of slides examined correlated independently with PanIN occurrence, accounting for the sampling effect. Age variable also showed a direct and independent correlation with PanIN probability, the adjusted odds ratio for a 1-year increase in age being 1.02. The other variables, location, gender, race, and history of diabetes, smoking, and alcohol consumption, did not correlate significantly with PanIN frequency in our model. Figure 4 illustrates a graphic representation of our multivariate regression model showing that even controlling for the number of slides examined and for the age, there is a progressive increase in frequency of PanIN-positive cases from normal pancreata to pancreatitis and to primary ductal adenocarcinoma. Also, in each diagnostic category, there is an increase in PanIN occurrence with age.

\section{DISCUSSION}

During the last decade, a wealth of knowledge has been accumulated regarding the molecular pathology of pancreatic cancer (30). It is recognized now that pancreatic carcinoma is a genetic disease produced by progressive mutations in cancerrelated genes (31). Among these, inactivation of the p16 (MTS1/INK4A/CDKN2) tumors suppressor gene has been reported as a frequent occurrence in several studies (approximately $95 \%$ of pancreatic cancers) $(30,32-40)$. It is closely followed by inactivation of p53 (50-75\% of cancers) $(30,33,34,37$, 41-50) and DPC4 tumor suppressor genes (55\% of cancers) (30, 33, 34, 37, 51-54). Among the oncogenes, activation by point mutation of the K-ras gene is found in almost all pancreatic carcinomas and appears to be an early event in carcinogenesis $(30,33,34,37,44,55-61)$.

Several investigators conducting morphologic studies of normal and neoplastic pancreata have reported putative precursor lesions for pancreatic carcinoma identified in the ductal system exhibiting various degrees of architectural changes (usually papillary or micropapillary) and cytological atypia (3-9). Those investigators based their assumption that these lesions are preneoplastic on the static observation that they are associated with ductal carcinoma and also on their morphologic similarity to cancer. It also seemed logical to search for the precursors of ductal carcinoma within the ductal elements. More convincing evidence was provided by Brat et al. (26) in a dynamic study in which the investigators reported on three patients who developed pancreatic ductal carcinoma 17 months to 10 years after identification of atypical papillary lesions in their pancreases. Brockie et al. (62) in a similar study reported two patients with dysplastic lesions who developed carcinoma 9 and 


\begin{tabular}{|c|c|c|c|c|c|}
\hline \multirow{2}{*}{ Diagnostic Category } & \multirow{2}{*}{ Mean Age (range) yr } & \multicolumn{2}{|c|}{ Sex ${ }^{1}$ Number (\%) } & \multicolumn{2}{|c|}{ Race $^{2}$ Number (\%) } \\
\hline & & M & $\mathrm{F}$ & CC & AA \\
\hline Non-neoplastic & $50.9(16-84)$ & $110(72 \%)$ & $42(28 \%)$ & $41(53 \%)$ & $37(47 \%)$ \\
\hline Normal & $40.4(16-79)$ & $25(69 \%)$ & $11(31 \%)$ & 7 (70\%) & $3(30 \%)$ \\
\hline Pancreatitis & $51.5(17-84)$ & $64(74 \%)$ & $22(26 \%)$ & $21(46 \%)$ & $25(54 \%)$ \\
\hline Sec Tumors & $62.1(35-80)$ & $21(70 \%)$ & $9(30 \%)$ & $13(59 \%)$ & $9(41 \%)$ \\
\hline DA & $66.7(43-87)$ & $33(41 \%)$ & $48(59 \%)$ & $44(75 \%)$ & $15(25 \%)$ \\
\hline Total & $56.4(16-87)$ & $143(61 \%)$ & $90(39 \%)$ & $85(62 \%)$ & $52(38 \%)$ \\
\hline
\end{tabular}

DA, ductal adenocarcinoma.

All percentages are rounded to the nearest integer.

${ }^{1}$ Gender data were available in 233 cases.

${ }^{2}$ Race data were available in 137 cases.

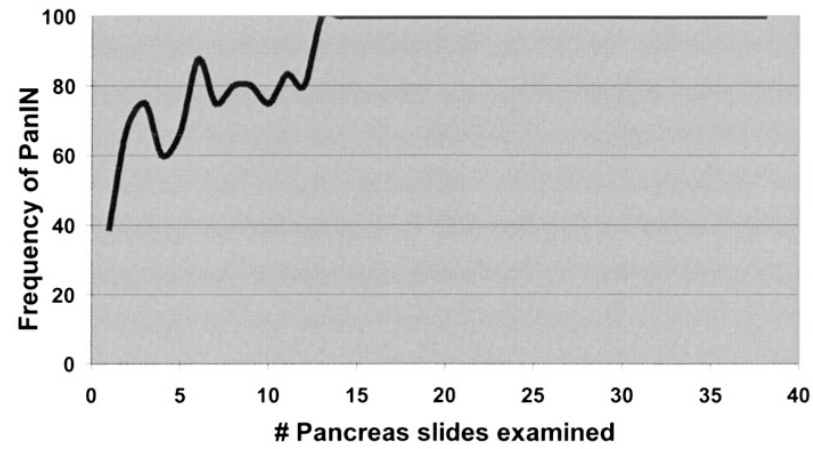

FIGURE 3. Correlation of number of pancreatic slides examined per case with the frequency of PanIN.

29 years later. In recent years, several investigators have demonstrated that the molecular alterations commonly found in pancreatic ductal adenocarcinoma (activation of K-ras oncogene and inactivation of p16, p53, and DPC4) are also encountered in PanIN lesions (16, 42, 63-72). Moreover it appears that the incidence of these alterations is increasing proportionally with the degree of cytological and architectural atypia (73). Yamano et al. (74), in an elegant study, microdissected a total of 126 foci of dysplastic and invasive pancreatic carcinoma and analyzed them for allelic loss. They found a progressive accumulation of allelic loss from what they referred to as intraductal nonpapillary hyperplasia to papillary hyperplasia to severe dysplasia and to invasive ductal adenocarcinoma, supporting the paradigm that the invasive component evolves through successive genetic changes from the intraductal component.

Until recently, a uniform classification of pancreatic intraductal lesions arising in small ducts was lacking. A study analyzing the degree of reproducibility in classifying intraductal lesions found little consensus between expert pancreatic pathologists (24). The reason for the lack of agreement was that $>70$ different diagnostic terms belonging to several distinct grading systems were used by the eight pathologists who were involved in that study and also that in several cases the diagnoses rendered for a single duct lesion ranged from hyperplasia to metaplasia to dysplasia to carcinoma in situ. Subsequently, those investigators agreed on a standard nomenclature and diagnostic criteria for these lesions, selecting the terminology pancreatic intraepithelial neoplasia (PanIN). This new classification system was then evaluated for reproducibility, which was fair for Grade 1 and 3 and poor for Grade 2 PanIN lesions (24).

Our study documents the frequency of intraductal pancreatic lesions in non-neoplastic pancreata as well as in glands involved by pancreatic ductal adenocarcinoma using the nomenclature and criteria defined by the recent consensus paper (24). We found a progressive increase in PanIN occurrence from so-called normal pancreata $(28 \%)$, to pancreatitis-considered a risk factor for carcinoma (63\%)—and to ductal adenocarcinoma (82\%). We also noted a progressive increase in the proportion of high-grade versus low-grade lesions from benign pancreata (displaying predominantly PanIN $1 \mathrm{~A}$ and $1 \mathrm{~B}$ ), to ductal adenocarcinoma (where $>50 \%$ of PanIN lesions were Grade 3). Because our data showed that the age of the patients as well as the number of slides examined in each case correlated with PanIN frequency, we analyzed a multivariate logistic regression model to evaluate the independent influence of each variable on the frequency of intraductal lesions. This model showed that there was a statistically significant direct correlation between the frequency of PanIN-positive cases and diagnostic categories (normal, pancreatitis, carcinoma), even controlling for age and sampling variables. Age showed a direct and independent correlation with PanIN frequency in a multivariate analysis. The other variables analyzed (gender, race, location, and history of diabetes, smoking, and alcohol consumption) did not show any significant correlation with PanIN frequency in either univariate or multivariate analysis.

Our findings constitute indirect support for the precancerous role attributed to PanIN lesions. The progressive increase in the frequency of PanIN lesions and also in the ratio of high-grade versus low-grade PanINs from normal pancreata to pan- 
Table 5. PanIN Frequency by Gender, Race, History of Diabetes, Smoking, and Alcohol Abuse (highest grade PanIN lesion used for assigning grade)

\begin{tabular}{|c|c|c|c|c|c|c|c|c|c|c|}
\hline & \multicolumn{2}{|c|}{ Gender pos/tot (\%) } & \multicolumn{2}{|c|}{ Race pos/tot (\%) } & \multicolumn{2}{|c|}{ Diabetes pos/tot (\%) } & \multicolumn{2}{|c|}{ Smoking pos/tot (\%) } & \multicolumn{2}{|c|}{ Alcohol pos/tot (\%) } \\
\hline & $\mathrm{M}$ & $\mathrm{F}$ & $\mathrm{CC}$ & AA & + & - & + & - & + & - \\
\hline PanIN (\%) & $85 / 143(59 \%)$ & $63 / 90(70 \%)$ & $56 / 85(66 \%)$ & $34 / 52(65 \%)$ & $11 / 14(79 \%)$ & $30 / 43(70 \%)$ & $36 / 52(69 \%)$ & 15/18 (83\%) & $12 / 20(60 \%)$ & $36 / 45(80 \%)$ \\
\hline$P$-value* & \multicolumn{2}{|c|}{0.1} & \multicolumn{2}{|c|}{0.9} & \multicolumn{2}{|c|}{0.5} & \multicolumn{2}{|c|}{0.2} & \multicolumn{2}{|c|}{0.09} \\
\hline
\end{tabular}

M, male; F, female; CC, Caucasian; AA, African-American.

All percentages are rounded to the nearest integer.

* Chi-square test.

Table 6. PanIN Frequency in Head versus Tail of the Pancreas (highest grade PanIN lesion used for assigning grade)

\begin{tabular}{lcccc}
\hline & & & Location & \\
\cline { 2 - 5 } & $\begin{array}{c}\text { Head } \\
\text { pos/tot (\%) }\end{array}$ & Tail Number (\%) & $\begin{array}{c}\text { Total Pancreatectomy } \\
\text { pos/tot (\%) }\end{array}$ & $\begin{array}{c}\text { Unknown } \\
\text { pos/tot (\%) }\end{array}$ \\
\hline PanIN 1A & $35 / 123(10 \%)$ & $12 / 70(17 \%)$ & $(0 \%)$ & $6 / 29(21 \%)$ \\
PanIN 1B & $19 / 123(15 \%)$ & $17 / 70(24 \%)$ & $4 / 12(33 \%)$ & $(0 \%)$ \\
PanIN 2 & $26 / 123(21 \%)$ & $8 / 70(11 \%)$ & $(0 \%)$ & $2 / 29(7 \%)$ \\
PanIN 3 & $30 / 123(24 \%)$ & $5 / 70(7 \%)$ & $4 / 12(33 \%)$ & $3 / 29(10 \%)$ \\
Total PanIN & $88 / 123(72 \%)$ & $42 / 70(60 \%)$ & & $16 / 29(55 \%)$ \\
\hline
\end{tabular}

All percentages are rounded to the nearest integer.

Table 7. Multivariate Logistic Regression Model

\begin{tabular}{|c|c|c|c|c|}
\hline Variable & $\beta$ coefficient & $P$-value & Odds Ratio & 95\% CI of Odds Ratio \\
\hline \multicolumn{5}{|l|}{ 1. Diagnostic } \\
\hline "Normal" & - & 0.03 & - & - \\
\hline $\mathrm{CP}$ & 1.19 & 0.012 & 3.3 & $1.3-8.4$ \\
\hline $2^{0}$ & 1.12 & 0.06 & 3.05 & $0.9-9.9$ \\
\hline DA & 1.55 & 0.005 & 4.7 & $1.6-14.15$ \\
\hline 2. No of examined slides & 0.17 & 0.0005 & 1.19 & $1.1-1.3$ \\
\hline 3. Age & 0.02 & 0.04 & 1.02 & $1.001-1.05$ \\
\hline 4. Location & Not significant & & & \\
\hline 5. Gender & Not significant & & & \\
\hline 6. Race & Not significant & & & \\
\hline 7. Hx of diabetes & Not significant & & & \\
\hline 8. Hx of smoking & Not significant & & & \\
\hline 9. Hx of alcohol consumption & Not significant & & & \\
\hline
\end{tabular}

CI, confidence interval; CP, chronic pancreatitis; $2^{0}$, secondary tumor group; DA, pancreatic ductal adenocarcinoma.

creatitis and to carcinoma is in keeping with the currently proposed model of pancreatic carcinogenesis, which hypothesizes a progression from normal epithelium to low-grade dysplasia (PanIN 1 and 2) to high-grade dysplasia/carcinoma in situ (PanIN 3) and to infiltrating carcinoma (10, 73, 75, 76). A significant finding in our study was the high frequency of PanIN 1A lesions, also formerly known as mucinous duct lesions or mucinous metaplasia, identified in pancreata without primary neoplasms. The frequency of "pure" PanIN 1A was 18\%; however, the total frequency of PanIN 1A lesions in this subgroup (including the cases that had a higher grade PanIN associated) was $43 \%$ (19\% in normal pancreata, $53 \%$ in pancreatitis, and $40 \%$ in secondary tumors), because most cases with PanIN 2 or 3 displayed also low-grade PanIN lesions. The ubiquitous presence of PanIN 1A in benign pancreata suggests that this group most likely includes both flat non-neoplastic and neoplastic lesions that are morphologically similar. The neoplastic PanIN 1A may represent the earliest step towards neoplasia,

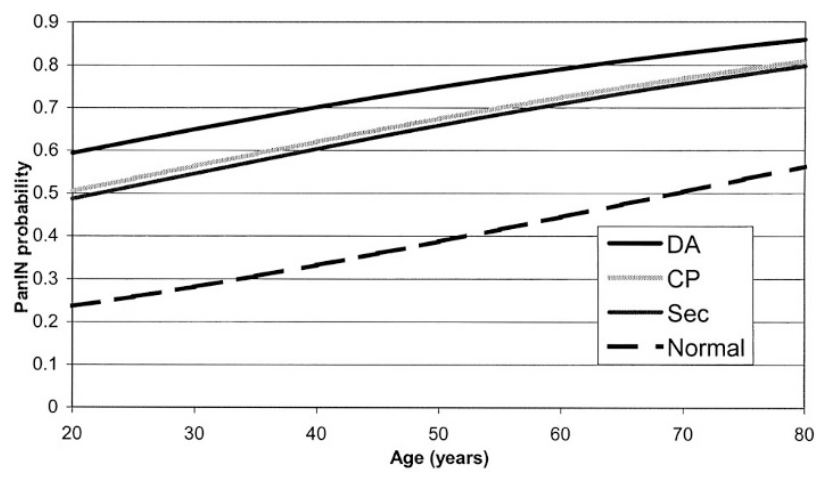

FIGURE 4. Graphic representation of the multivariate logistic regression model. The number of examined slides was set at 5.3 slides/ case (mean value in our study). CP, chronic pancreatitis; DA, ductal adenocarcinoma; Sec, secondary tumors.

and only a very small percentage of them will progress eventually to higher-grade lesions and invasive carcinoma. In keeping with this, molecular studies have showed that a proportion of nonatypical flat intraductal lesions display K-ras mutations, 
HER-2/neu overexpression, and very rare p16 mutations $(63,64,66,68,69,77,78)$. It has been agreed by several investigators that K-ras mutation represents the earliest step in carcinogenesis and that additional genetic alterations are required for progression towards carcinoma $(64,68,79)$. As such, PanIN 1 lesions represent the equivalent of lowgrade prostatic intraepithelial neoplasia (PIN) or of the aberrant crypt foci found in the gastrointestinal tract, which also display K-ras mutations (80).

We identified a trend in our study for an increased occurrence of PanIN lesions in the head of the pancreas versus in the tail $(72 \%$ versus $60 \%$, respectively). These findings are in concordance with the results of Kozuka et al. (5) but not with those of Luttges et al. (16), who found dysplastic lesions to be evenly distributed throughout the pancreas. Also pancreatic head adenocarcinomas were more often associated with PanIN lesions than tail cancers (84\% versus $69 \%$, respectively). This increased incidence of dysplasia in the head of the pancreas compared with in the tail may represent a potential explanation for the preferred localization of ductal adenocarcinoma in the head of the gland.

Interestingly, the group of secondary tumors that is metastatic to the pancreas displayed a frequency of PanIN-positive cases (60\%) similar to that of the chronic pancreatitis group (63\%). Within this group of secondary tumors, there was a difference in PanIN frequency between pancreases with associated fibrosis and atrophic changes versus those without atrophy ( $72 \%$ versus $43 \%$ ). Moreover, the case displaying a focus of PanIN 3 was from the subgroup with pancreatic atrophy. Although the small number of cases in this diagnostic category prevents us from formulating statistically significant correlations, one explanation for these findings could be that the increase incidence of PanIN is related to pancreatic fibrosis and atrophy that is present in $60 \%$ of pancreata with secondary tumors. Another potential mechanism might be local (paracrine) induction of PanIN by the metastatic tumor.

The present study complements previous morphologic investigations that analyzed the presence of hyperplastic and dysplastic lesions in nonneoplastic and neoplastic pancreas. Kozuka et al. (5), in a study examining 1174 pancreata from autopsy specimens, found an increase in the occurrence of nonpapillary, papillary, and atypical hyperplasia in cancerous pancreata versus nonneoplastic ones. Luttges et al. (16) found on 140 non-neoplastic pancreata an incidence of mucinous cell hypertrophy, ductal papillary hyperplasia, and adenomatoid ductal hyperplasia of $68 \%, 36 \%$, and $40 \%$, respectively. These lesions are probably similar to PanIN 1A and 1B lesions that we found in $51 \%$ of non-neoplastic pancreata (absolute PanIN $1 \mathrm{~A}$ and $1 \mathrm{~B}$ frequency, regardless of whether higher grade lesions were present). The present study is nevertheless, to our knowledge, the first one that comprehensively investigates pancreatic dysplasia using the new consensus criteria for defining PanIN lesions. As opposed to the previous reports, it will allow direct comparison to results of similar studies that used the same criteria in defining PanIN lesions. A more clear image of PanIN incidence in various patient groups, including the ones at high risk for developing pancreatic carcinoma, would be helpful for future studies attempting to design screening tests for detection of precancerous lesions.

\section{REFERENCES}

1. Greenlee RT, Murray T, Bolden S, Wingo PA. Cancer statistics, 2000. C A Cancer J Clin 2000;50:7-33.

2. Kern S, Hruban R, Hollingsworth MA, Brand R, Adrian TE, Jaffee E, et al. A white paper: the product of a pancreas cancer think tank. Cancer Res 2001;61:4923-32.

3. Sommers SC, Murphy SA, Warren S. Pancreatic duct hyperplasias and cancer. Gastroenterology 1954;27:629-40.

4. Cubilla AL, Fitzgerald PJ. Morphological lesions associated with human primary invasive nonendocrine pancreas cancer. Cancer Res 1976;36:2690-8.

5. Kozuka S, Sassa R, Taki T, Masamoto K, Nagasawa S, Saga S, et al. Relation of pancreatic duct hyperplasia to carcinoma. Cancer 1979;43:1418-28.

6. Kloppel G, Bommer G, Ruckert K, Seifert G. Intraductal proliferation in the pancreas and its relationship to human and experimental carcinogenesis. Virchows Arch A Pathol Anat Histol 1980;387:221-33.

7. Chen J, Baithun SI, Ramsay MA. Histogenesis of pancreatic carcinomas: a study based on 248 cases. J Pathol 1985;146: 65-76.

8. Furukawa T, Chiba R, Kobari M, Matsuno S, Nagura H, Takahashi T. Varying grades of epithelial atypia in the pancreatic ducts of humans. Classification based on morphometry and multivariate analysis and correlated with positive reactions of carcinoembryonic antigen. Arch Pathol Lab Med 1994;118:227-34.

9. Bentjerodt R, Smok G. Ductal epithelial lesions and pancreatic adenocarcinoma. Rev Med Chil 1990;118:1099-104.

10. Kloppel G, Solcia E, Longnecker D, Capella C, L.H.S. World Health Organization. Histological typing of tumours of the exocrine pancreas. 2nd ed. Berlin: Springer-Verlag; 1996.

11. Stamm BH. Incidence and diagnostic significance of minor pathologic changes in the adult pancreas at autopsy: a systematic study of 112 autopsies in patients without known pancreatic disease. Hum Pathol 1984;15:677-83.

12. Kishi K, Nakamura K, Yoshimori M, Tajiri H, Ozaki H, Kinoshita T, et al. Morphology and pathological significance of focal acinar cell dysplasia of the human pancreas. Pancreas 1992;7:177-82.

13. Schulz HJ. Dysplasia and carcinoma in situ of the pancreatic duct epithelium. Zentralbl Allg Pathol 1988;134:3-14.

14. Agoff SN, Crispin DA, Bronner MP, Dail DH, Hawes SE, Haggitt RC. Neoplasms of the ampulla of vater with concurrent pancreatic intraductal neoplasia: a histological and molecular study. Mod Pathol 2001;14:139-46.

15. Pour PM, Sayed S, Sayed G. Hyperplastic, preneoplastic and neoplastic lesions found in 83 human pancreases. Am J Clin Pathol 1982;77:137-52.

16. Luttges J, Reinecke-Luthge A, Mollmann B, Menke MA, Clemens A, Klimpfinger M, et al. Duct changes and K-ras mu- 
tations in the disease-free pancreas: analysis of type, age relation and spatial distribution. Virchows Arch 1999;435: 461-8.

17. Chiaramondia M, Ceppa P. Epithelial dysplasia and stroma changes in chronic pancreatitis and carcinoma of the exocrine pancreas. Morphologico-functional correlations. Pathologica 1988;80:561-72.

18. Cylwik B, Nowak HF, Puchalski Z, Barczyk J. Chronic pancreatitis as a predisposing factor in the development of pancreatic cancer. Histological and histochemical studies. Zentralbl Allg Pathol 1985;130:217-24.

19. Cylwik B, Nowak HF, Puchalski Z, Barczyk J. Epithelial anomalies in chronic pancreatitis as a risk factor of pancreatic cancer. Hepatogastroenterology 1998;45:528-32.

20. Tannapfel A, Witzigmann H, Wittekind C. Pancreatic intraepithelial neoplasia in chronic pancreatitis. Zentralbl Chir 2001;126:879-83.

21. Volkholz H, Stolte M, Becker V. Epithelial dysplasias in chronic pancreatitis. Virchows Arch A Pathol Anat Histol 1982;396:331-49.

22. Tomaszewska R, Okon K, Nowak K, Stachura J. Proliferation index and karyometric features of pancreatic intraductal proliferative lesions. Anal Cell Pathol 1999;19:175-85.

23. Mukada T, Yamada S. Dysplasia and carcinoma in situ of the exocrine pancreas. Tohoku J Exp Med 1982;137:115-24.

24. Hruban RH, Adsay NV, Albores-Saavedra J, Compton C, Garrett ES, Goodman SN, et al. Pancreatic intraepithelial neoplasia: a new nomenclature and classification system for pancreatic duct lesions. Am J Surg Pathol 2001;25:579-86.

25. Klimstra DS, Longnecker DS. K-ras mutations in pancreatic ductal proliferative lesions. Am J Pathol 1994;145:1547-50.

26. Brat DJ, Lillemoe KD, Yeo CJ, Warfield PB, Hruban RH. Progression of pancreatic intraductal neoplasias to infiltrating adenocarcinoma of the pancreas. Am J Surg Pathol 1998; 22:163-9.

27. Lowenfels $A B$, Maisonneuve P, Cavallini G, Ammann RW, Lankisch PG, Andersen JR, et al. Pancreatitis and the risk of pancreatic cancer. International Pancreatitis Study Group. N Engl J Med 1993;328:1433-7.

28. Lowenfels $\mathrm{AB}$, Maisonneuve $\mathrm{P}$, Lankisch PG. Chronic pancreatitis and other risk factors for pancreatic cancer. Gastroenterol Clin North Am 1999;28:673-85.

29. Kleinbaum DG. Logistic regression: a self-learning text. New York: Springer; 1994.

30. Hruban RH, Iacobuzio-Donahue C, Wilentz RE, Goggins M, Kern SE. Molecular pathology of pancreatic cancer. Cancer J 2001;7:251-8.

31. Hruban RH, Petersen GM, Ha PK, Kern SE. Genetics of pancreatic cancer. From genes to families. Surg Oncol Clin N Am 1998;7:1-23.

32. Schutte M, Hruban RH, Geradts J, Maynard R, Hilgers W, Rabindran SK, et al. Abrogation of the Rb/p16 tumorsuppressive pathway in virtually all pancreatic carcinomas. Cancer Res 1997;57:3126-30.

33. Moore PS, Sipos B, Orlandini S, Sorio C, Real FX, Lemoine NR, et al. Genetic profile of 22 pancreatic carcinoma cell lines. Analysis of K-ras, p53, p16 and DPC4/Smad4. Virchows Arch 2001;439:798-802.

34. Moore PS, Orlandini S, Zamboni G, Capelli P, Rigaud G, Falconi M, et al. Pancreatic tumours: molecular pathways implicated in ductal cancer are involved in ampullary but not in exocrine nonductal or endocrine tumorigenesis. Br J Cancer 2001;84:253-62.

35. Caldas C, Hahn SA, da Costa LT, Redston MS, Schutte M, Seymour AB, et al. Frequent somatic mutations and homozygous deletions of the p16 (MTS1) gene in pancreatic adenocarcinoma. Nat Genet 1994;8:27-32.

36. Naumann M, Savitskaia N, Eilert C, Schramm A, Kalthoff H, Schmiegel W. Frequent codeletion of p16/MTS1 and p15/
MTS2 and genetic alterations in p16/MTS1 in pancreatic tumors. Gastroenterology 1996;110:1215-24.

37. Rozenblum E, Schutte M, Goggins M, Hahn SA, Panzer S, Zahurak M, et al. Tumor-suppressive pathways in pancreatic carcinoma. Cancer Res 1997;57:1731-4.

38. Bartsch D, Shevlin DW, Callery MP, Norton JA, Wells SA Jr, Goodfellow PJ. Reduced survival in patients with ductal pancreatic adenocarcinoma associated with CDKN2 mutation. J Natl Cancer Inst 1996;88:680-2.

39. Hu YX, Watanabe H, Ohtsubo K, Yamaguchi Y, Ha A, Okai T, et al. Frequent loss of p16 expression and its correlation with clinicopathological parameters in pancreatic carcinoma. Clin Cancer Res 1997;3:1473-7.

40. Geradts J, Hruban RH, Schutte M, Kern SE, Maynard R. Immunohistochemical p16INK4a analysis of archival tumors with deletion, hypermethylation, or mutation of the CDKN2/ MTS1 gene. A comparison of four commercial antibodies. Appl Immunohistochem Mol Morphol 2000;8:71-9.

41. Zhang SY, Ruggeri B, Agarwal P, Sorling AF, Obara T, Ura H, et al. Immunohistochemical analysis of p53 expression in human pancreatic carcinomas. Arch Pathol Lab Med 1994; 118:150-4.

42. DiGiuseppe JA, Hruban RH, Goodman SN, Polak M, van den Berg FM, Allison DC, et al. Overexpression of p53 protein in adenocarcinoma of the pancreas. Am J Clin Pathol 1994;101: 684-8.

43. Boschman CR, Stryker S, Reddy JK, Rao MS. Expression of p53 protein in precursor lesions and adenocarcinoma of human pancreas. Am J Pathol 1994;145:1291-5.

44. Hahn SA, Kern SE. Molecular genetics of exocrine pancreatic neoplasms. Surg Clin North Am 1995;75:857-69.

45. Ruggeri B, Zhang SY, Caamano J, DiRado M, Flynn SD, Klein-Szanto AJ. Human pancreatic carcinomas and cell lines reveal frequent and multiple alterations in the p53 and Rb-1 tumor-suppressor genes. Oncogene 1992;7:1503-11.

46. Redston MS, Caldas C, Seymour AB, Hruban RH, da Costa L, Yeo CJ, et al. p53 mutations in pancreatic carcinoma and evidence of common involvement of homocopolymer tracts in DNA microdeletions. Cancer Res 1994;54:3025-33.

47. Berrozpe G, Schaeffer J, Peinado MA, Real FX, Perucho M. Comparative analysis of mutations in the p53 and K-ras genes in pancreatic cancer. Int J Cancer 1994;58:185-91.

48. Coppola D, Lu L, Fruehauf JP, Kyshtoobayeva A, Karl RC, Nicosia SV, et al. Analysis of p53, p21WAF1, and TGF-betal in human ductal adenocarcinoma of the pancreas: TGFbetal protein expression predicts longer survival. Am J Clin Pathol 1998;110:16-23.

49. Lee EU, Cibull ML, O’Daniel-Pierce E, Strodel WE, Jennings CD. Expression of p53 protein in pancreatic adenocarcinoma. Relationship to cigaret smoking. Int J Pancreatol 1995; 17:237-42.

50. Lundin J, Nordling S, von Boguslawsky K, Roberts PJ, Haglund C. Prognostic value of immunohistochemical expression of p53 in patients with pancreatic cancer. Oncology 1996;53:104-11.

51. Hahn SA, Schutte M, Hoque AT, Moskaluk CA, da Costa LT, Rozenblum E, et al. DPC4, a candidate tumor suppressor gene at human chromosome 18q21.1. Science 1996;271: 350-3.

52. Schutte M. DPC4/SMAD4 gene alterations in human cancer, and their functional implications. Ann Oncol 1999;10(Suppl 4):56-9.

53. Schutte M, Hruban RH, Hedrick L, Cho KR, Nadasdy GM, Weinstein CL, et al. DPC4 gene in various tumor types. Cancer Res 1996;56:2527-30.

54. Wilentz RE, Su GH, Dai JL, Sparks AB, Argani P, Sohn TA, et al. Immunohistochemical labeling for dpc4 mirrors genetic status in pancreatic adenocarcinomas: a new marker of DPC4 inactivation. Am J Pathol 2000;156:37-43. 
55. Almoguera C, Shibata D, Forrester K, Martin J, Arnheim N, Perucho M. Most human carcinomas of the exocrine pancreas contain mutant c-K-ras genes. Cell 1988;53:549-54.

56. Smit VT, Boot AJ, Smits AM, Fleuren GJ, Cornelisse CJ, Bos JL. KRAS codon 12 mutations occur very frequently in pancreatic adenocarcinomas. Nucleic Acids Res 1988;16:777382.

57. Pellegata NS, Sessa F, Renault B, Bonato M, Leone BE, Solcia $\mathrm{E}$, et al. K-ras and p53 gene mutations in pancreatic cancer: ductal and nonductal tumors progress through different genetic lesions. Cancer Res 1994;54:1556-60.

58. Kalthoff H, Schmiegel W, Roeder C, Kasche D, Schmidt A, Lauer G, et al. p53 and K-RAS alterations in pancreatic epithelial cell lesions. Oncogene 1993;8:289-98.

59. Hruban RH, van Mansfeld AD, Offerhaus GJ, van Weering DH, Allison DC, Goodman SN, et al. K-ras oncogene activation in adenocarcinoma of the human pancreas. A study of 82 carcinomas using a combination of mutant-enriched polymerase chain reaction analysis and allele-specific oligonucleotide hybridization. Am J Pathol 1993;143:545-54.

60. Scarpa A, Capelli P, Villaneuva A, Zamboni G, Lluis F, Accolla $\mathrm{R}$, et al. Pancreatic cancer in Europe: Ki-ras gene mutation pattern shows geographical differences. Int J Cancer 1994; 57:167-71.

61. Motojima K, Urano T, Nagata Y, Shiku H, Tsurifune T, Kanematsu T. Detection of point mutations in the Kirsten-ras oncogene provides evidence for the multicentricity of pancreatic carcinoma. Ann Surg 1993;217:138-43.

62. Brockie E, Anand A, Albores-Saavedra J. Progression of atypical ductal hyperplasia/carcinoma in situ of the pancreas to invasive adenocarcinoma. Ann Diagn Pathol 1998;2:286-92.

63. Wilentz RE, Geradts J, Maynard R, Offerhaus GJ, Kang M, Goggins $\mathrm{M}$, et al. Inactivation of the p16 (INK4A) tumorsuppressor gene in pancreatic duct lesions: loss of intranuclear expression. Cancer Res 1998;58:4740-4.

64. Moskaluk CA, Hruban RH, Kern SE. p16 and K-ras gene mutations in the intraductal precursors of human pancreatic adenocarcinoma. Cancer Res 1997;57:2140-3.

65. Apple SK, Hecht JR, Lewin DN, Jahromi SA, Grody WW, Nieberg RK. Immunohistochemical evaluation of K-ras, p53, and HER-2/neu expression in hyperplastic, dysplastic, and carcinomatous lesions of the pancreas: evidence for multistep carcinogenesis. Hum Pathol 1999;30:123-9.

66. DiGiuseppe JA, Hruban RH, Offerhaus GJ, Clement MJ, van den Berg FM, Cameron JL, et al. Detection of K-ras mutations in mucinous pancreatic duct hyperplasia from a patient with a family history of pancreatic carcinoma. Am J Pathol 1994;144:889-95.

67. Sugio K, Molberg K, Albores-Saavedra J, Virmani AK, Kishimoto Y, Gazdar AF. K-ras mutations and allelic loss at $5 \mathrm{q}$ and $18 q$ in the development of human pancreatic cancers. Int $\mathrm{J}$ Pancreatol 1997;21:205-17.
68. Terhune PG, Phifer DM, Tosteson TD, Longnecker DS. K-ras mutation in focal proliferative lesions of human pancreas. Cancer Epidemiol Biomarkers Prev 1998;7:515-21.

69. Luttges J, Diederichs A, Menke MA, Vogel I, Kremer B, Kloppel G. Ductal lesions in patients with chronic pancreatitis show K-ras mutations in a frequency similar to that in the normal pancreas and lack nuclear immunoreactivity for p53. Cancer 2000;88:2495-504.

70. Luttges J, Galehdari H, Brocker V, Schwarte-Waldhoff I, Henne-Bruns D, Kloppel G, et al. Allelic loss is often the first hit in the biallelic inactivation of the p53 and DPC4 genes during pancreatic carcinogenesis. Am J Pathol 2001;158: 1677-83.

71. Heinmoller E, Dietmaier W, Zirngibl H, Heinmoller P, Scaringe $\mathrm{W}$, Jauch $\mathrm{KW}$, et al. Molecular analysis of microdissected tumors and preneoplastic intraductal lesions in pancreatic carcinoma. Am J Pathol 2000;157:83-92.

72. Wilentz RE, Iacobuzio-Donahue CA, Argani P, McCarthy DM, Parsons JL, Yeo CJ, et al. Loss of expression of Dpc4 in pancreatic intraepithelial neoplasia: evidence that DPC4 inactivation occurs late in neoplastic progression. Cancer Res 2000;60:2002-6.

73. Hruban RH, Goggins M, Parsons J, Kern SE. Progression model for pancreatic cancer. Clin Cancer Res 2000;6:296972.

74. Yamano M, Fujii H, Takagaki T, Kadowaki N, Watanabe H, Shirai T. Genetic progression and divergence in pancreatic carcinoma. Am J Pathol 2000;156:2123-33.

75. Hruban RH, Wilentz RE, Goggins M, Offerhaus GJ, Yeo CJ, Kern SE. Pathology of incipient pancreatic cancer. Ann Oncol 1999;10(Suppl 4):9-11.

76. Hruban RH, Wilentz RE, Kern SE. Genetic progression in the pancreatic ducts. Am J Pathol 2000;156:1821-5.

77. Tada M, Omata M, Kawai S, Saisho H, Ohto M, Saiki RK, et al. Detection of ras gene mutations in pancreatic juice and peripheral blood of patients with pancreatic adenocarcinoma. Cancer Res 1993;53:2472-4.

78. Day JD, Digiuseppe JA, Yeo C, Lai-Goldman M, Anderson SM, Goodman SN, et al. Immunohistochemical evaluation of HER-2/neu expression in pancreatic adenocarcinoma and pancreatic intraepithelial neoplasms. Hum Pathol 1996;27: $119-24$

79. Tada M, Ohashi M, Shiratori Y, Okudaira T, Komatsu Y, Kawabe T, et al. Analysis of K-ras gene mutation in hyperplastic duct cells of the pancreas without pancreatic disease. Gastroenterology 1996;110:227-31.

80. Smith AJ, Stern HS, Penner M, Hay K, Mitri A, Bapat BV, et al. Somatic APC and K-ras codon 12 mutations in aberrant crypt foci from human colons. Cancer Res 1994;54: 5527-30. 